\title{
On Model D Opener
}

\author{
By Kunio Aoki, Akira Aoki, Tokuichi Tanimoto \\ and Noboru Arita, Members, TMSJ \\ Daiwa Spinning Co., Ltd.
}

\begin{abstract}
The rotary type beater, such as the saw toothed beater of a cotton opener and picker, performs good opening action, but for effective cleaning action a special mechanism is needed.

Model D Opener of our designing is intended for effective cleaning and has given good results. In this report we describe the mechanical feature of our new opener and report the results of tests by some mills. This opener is also good for the short-cut system of opening and picking process for cotton and for the opening process for rayon.
\end{abstract}

\section{Introduction}

A saw-toothed wire cylinder gives a remarkable opening effect. This has been clearly know through our experience of the action of lickerin rollers of carding engines. This effective opening action is applied to our newly designed opener. A laboratory test of the new-model opener was completed in 1954 with good results, i.e., good opening and cleaning effects, uniformity of lap-thickness and absence of fiber damage. A mill test made over the past two years has demonstrated the superiority of Model D Opener in opening and cleaning action to the conventional opener. Another test of the one-process opening and picking system with Model D Opener is now in progress, and latest data from the mill where the test is being made show that we may expect equally good results.

\section{Features of Model D Opener}

Model D Opener, with its production rate of up to $500 \mathrm{lbs} / \mathrm{hr}$, can substitute (1) a finishing picker, (2) the short cut system of opening and picking for cotton, and (3) the opening process for rayon. It gives better opening and cleaning action than the conventional machine without causing fiber damage. Therefore, it blends lint satisfactorily and gives good uniformity in the thickness of lap. In waste spinning, it separates lint and non-lint of waste cotton.

\section{Construction}

Figures 1 and 2 show the main construction of Model D Opener.

\section{2-1. Feeding and Opening}

The main part of this opener is a carding cylinder with specially designed saw-toothed

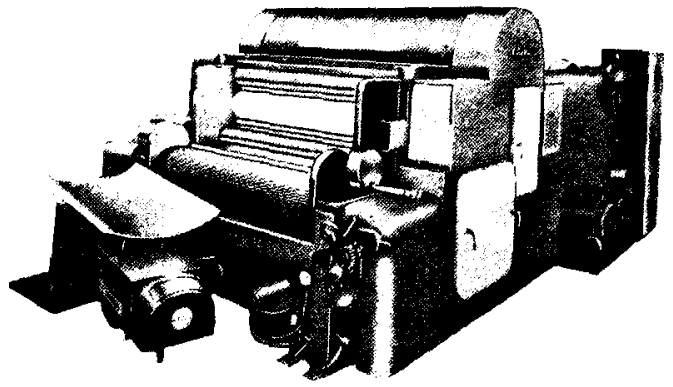

Fig. 1 General view of Model D Opener.

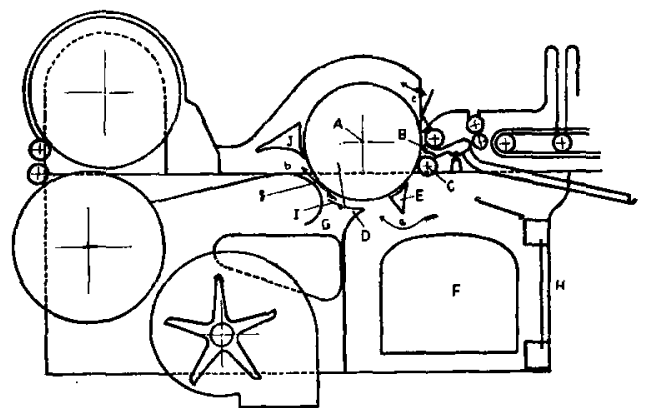

Fig. 2. Construction of Model D Opener

wire or spick on the cylinder surface. The cylinder diameter is 18 inches for one example. To obtain better feeding, more uniform opening and better cleaning action, the feed system of Model D Opener is equipped with newly designed pedals. The nose the pedal forms a special shape which enables uniform carding action. To help obtain more uniform opening action, a garnet roller, 3 inches in diameter, is provided under pedal $B$.

\subsection{Separation of Lint and Non-Lint}

The principle of the separation of lint and non-lint is based on the difference in the floating capacity of lint and non-lint. Separation is done in the opening part, which consists of cylinder $A$, pedal $B$ and garnet roller $C$, in the 
space between $C$ and sheet $D$ in Figure 2. For effectual separation of non-lint from lint, it is necessary to keep the intensity of air stream $a$ at a minimum and also to stabilize the eddy current in dust box $F$. In other words, if the above-mentioned conditions can be kept, the air condition of the dust box will approximate the dead air condition. For this purpose, the opener is so designed that the air supplied from inlets $G$ and $H$ is sucked into the cage fan. The special-shaped mote-knife $E$, controls the air courrent as shown in Figure 2 to obtain high cleaning efficiency. The lint percentage is adjusted by controlling position $E$ and the quantity of air coming from air-inlet $G$.

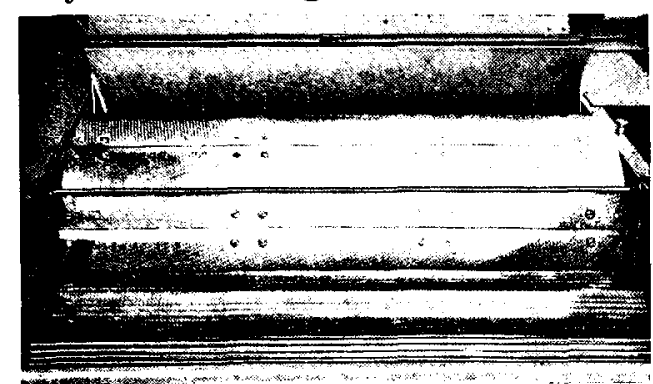

Fig. 3 Spicked cylinder.

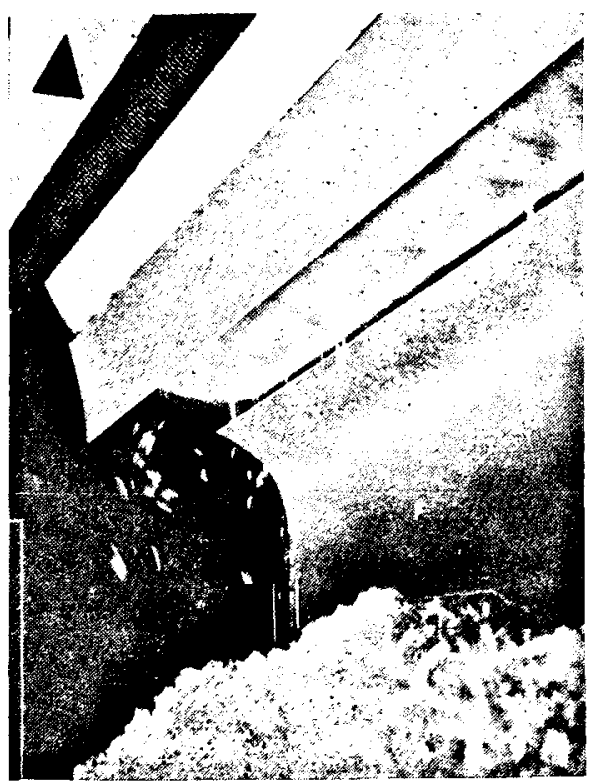

Fig. 4 Saw-toothed wire cylinder.

\section{2-3. Stripping by Air}

Stripping lint from the carding cylinder is also a key function of a carding cylinder type opener. The stripning system of Model D Opener has been chosen in the light of the results of our fundamental laboratory test. It is a system based on the principle of removing cotton lint from the edges of the saw teeth of the carding cylinder by means of the jet air stream which passes through the space between the sheet and the cylinder, and goes to the cage,
For smooth stripping of lint from the edges of the saw teeth of the cylinder, the air pressures of the air inlet sections have to be kept balanced so as to get a high speed of the air jet stream which passes through the saw teeth of cylinder $A$ to the cage at point $q$. The stream line of the air jet is tangent to the circle of the saw teeth of cylinder $A$ at point $q$. The speed of the air jet has to be kept higher than the surface speed of the saw-toothedi cylinder.

The air inlet under cylinder $A$ and adjustable air control plate $I$ Figure 2 are designed to meet these conditions. The space between the cylinder cover and cylinder $A$ are designed to be large enough for better stripping and cleaning action.

\section{2-4. Controlled Stripping Rail}

Controlled stripping rail $J$ is designed to keep the pressure balance of air streams $b$ and $c$, to obtain a uniform distribution of line to the cage surface and to prevent the licking of lap. This stripping rail is specially shaped; the setting and position of the rail have been determined by our theoretical consideration and by a laboratory test.

\section{Results Obtained}

We have obtained reliable data from our mill tests. We give the following data on our Model D Opener when it is used as a Finisher Scutcher for cotton spinning.

\section{3-1. Conditions of Mill Test}

For a reliable comparison of actions, we used for the test the same kind of raw cotton, the same spinning conditions, the same machine setting and the same gauge which are used in a test of the conventional opener.

\section{3-1-1. Raw stock}

Cotton:

Raw cotton for the spinning of Daiwa Spinning Co.'s 10's, 20's, 30's, 40's, yarns

Spun rayon:

Corona brand, C.D. 2 den $\times 2$ in, a Daiwa product

3-1-2. Arrangement of blending and picking machine

For cotton 10's and 20's

$\mathrm{HBB}-\mathrm{HM}-\mathrm{PO}-\mathrm{CO}-\mathrm{CO}-\mathrm{HO}-$

$\mathrm{HF}-\mathrm{DBO}^{*}$ and Model D Opener

For cotton 30's, 40's

$$
\mathrm{HBB} \text { - HM - PO CO HO - HF - }
$$

DBO* $^{*}$ and Model D Opener

For spun rayon 30 's

$$
\underset{\text { Opener }}{\mathrm{HBB}}-\mathrm{CO}-\mathrm{HO}-\mathrm{DBO}^{*} \text { and Model D }
$$

(*Double Beater Opener) 
3-1-3. R.P.M. of Beater

Conventional Finisher Scutcher

Cotton 10's, 20's 30's: 3-blade Beater

Cotton 40's :

3-blade Kirschner Beater 830 r.p.m.

Spun rayon 30 's :

3-blade Kirschner Beater 900 r.p.m.

Model D Opener

Cotton 10's, 20's, 30's :

Spicked cylinder

600 r.p.m.

\begin{tabular}{ccccc} 
Table 1 \\
\hline
\end{tabular}

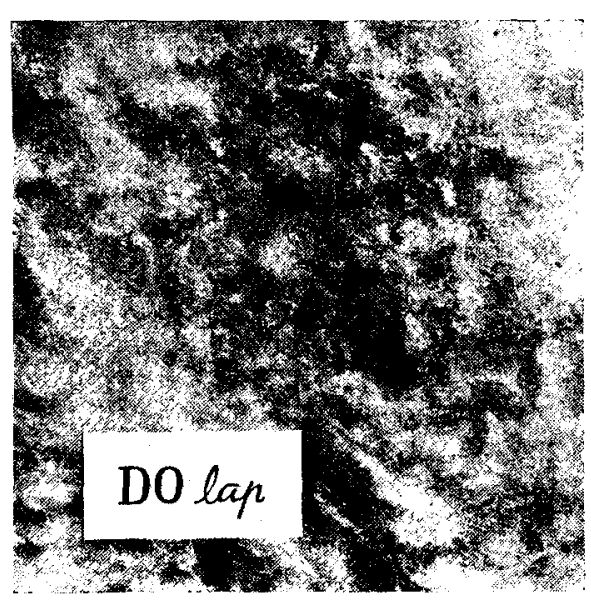

Fig. 5 Cotton

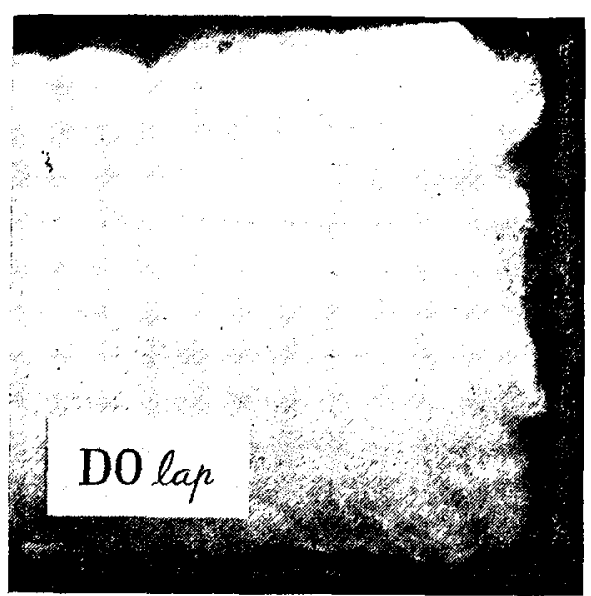

Spun rayon 30 's :

Spicked cylinder

400 r.p.m.

3-1-4. Production rate and weight of lap (oz/yd)

3-1-5. Spinning process after carding operation

Cotton $10^{\prime} \mathrm{s} \sim 30^{\prime} \mathrm{s}$ :

Carding engine - Drawing 3-head Model roving frame - Ring spinning frame (10's-Model $0 M$ high draft system, 20's and 30's-Model TN, 4 line apron draft system)

Cotton 40's :

Carding engine - Drawing 3-head - Ring spinning frame (Model OM super high draft system)

Spun rayon 30 's :

Carding engine - Drawing 2-head - Ring spinning frame (Mocel OM super high draft system)

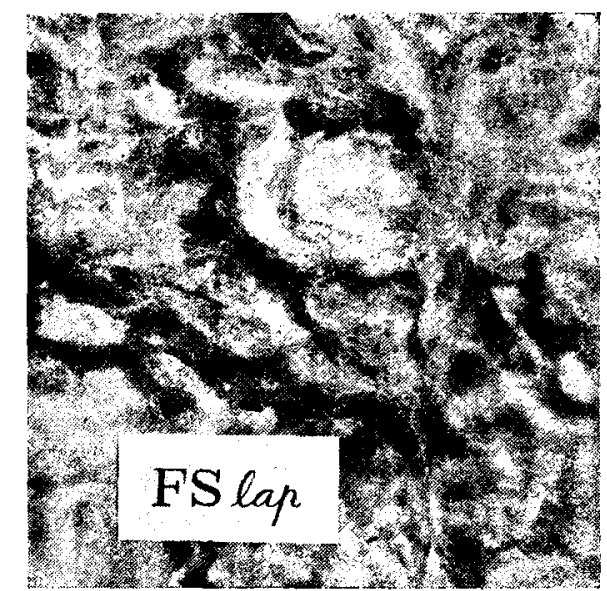

$30^{\prime} s$

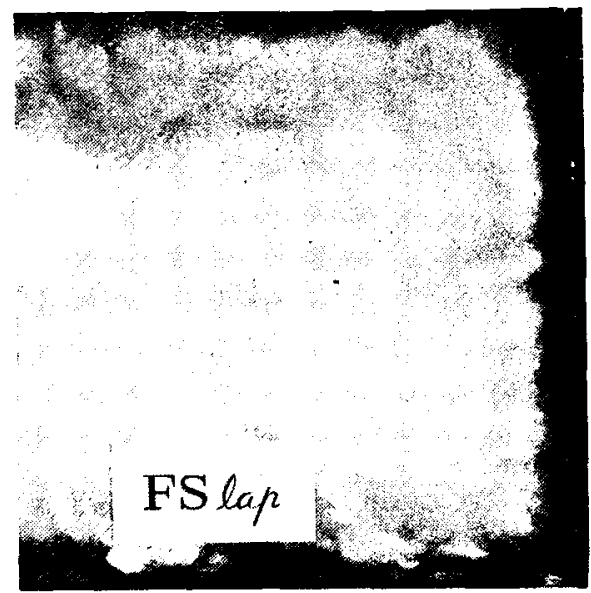

Fig. 6 Rayon $30^{\prime} s$ 


\section{3-2. Results Obtained}

3-2-1. Opening index (on $30^{\prime}$ s)

Table 2

\begin{tabular}{|c|c|c|c|c|c|c|}
\hline & $\begin{array}{l}\text { Raw } \\
\text { stock }\end{array}$ & $\mathrm{BDO}$ & FS & $\begin{array}{l}\text { Model D } \\
\text { Opener }\end{array}$ & $\begin{array}{c}\text { Compa- } \\
\text { rative } \\
\text { index }\end{array}$ & Note \\
\hline $\begin{array}{l}\text { Cotton (1) } \\
\text { Spun } \\
\text { rayon }\end{array}$ & $\begin{array}{l}32 \\
40(\mathrm{HF})\end{array}$ & $\begin{array}{r}120 \\
81\end{array}$ & $\begin{array}{r}126 \\
83\end{array}$ & $\begin{array}{r}143 \\
92\end{array}$ & $\begin{array}{l}113 \\
111\end{array}$ & $\begin{array}{l}\text { Fig.5 } \\
\text { Fig.6 }\end{array}$ \\
\hline
\end{tabular}

* Comparative index $=\frac{\text { Opening index of DO }}{\text { Opening index of FS }}$

N.B. (1) Measurement was done with the testing machine designed by Asst. Prof. Narumi, Shizuoka Univer sity

(2) Measurement was done with the testing machine designed by Asst. Prof. Kato of Fukui University and referred to in Journal of The Textile Machinery Society, Japanese edition, Sep. 1955 issue.

\section{3-2-2. Cleaning efficiency (30's)}

Cleaning efficiency, analyzed by a Shirley analyzer, is shown in Table 3.

\begin{tabular}{|c|c|c|c|}
\hline & $\begin{array}{c}\text { Model } \\
\text { Non-lint* } \\
(\%) \\
\end{array}$ & $\begin{array}{l}\text { Opener } \\
\text { Waste } \\
\text { (\%) }\end{array}$ & $\begin{array}{l}\text { Cleaning } \\
\text { efficiency** }\end{array}$ \\
\hline \multicolumn{4}{|l|}{ Products } \\
\hline $\begin{array}{l}\text { DBO lap } \\
\text { Finisher lap }\end{array}$ & $\begin{array}{l}2.15 \\
1.92\end{array}$ & $\overline{-}$ & $\overline{-}$ \\
\hline \multicolumn{4}{|l|}{ Waste } \\
\hline \multirow[t]{3}{*}{$\begin{array}{l}\text { Under beater } \\
\text { or cylinder }\end{array}$} & 48.07 & 0.40 & 0.91 \\
\hline & \multicolumn{3}{|c|}{ Conventional Opener } \\
\hline & $\begin{array}{c}\text { Non-lint* } \\
(\%)\end{array}$ & $\begin{array}{c}\text { Waste } \\
(\%)\end{array}$ & $\begin{array}{l}\text { Cleaning } \\
\text { efficiency** }\end{array}$ \\
\hline \multicolumn{4}{|l|}{ Products } \\
\hline DBO lap & 2.15 & - & - \\
\hline Finisher lop & 2.09 & - & - \\
\hline \multicolumn{4}{|l|}{ Waste } \\
\hline $\begin{array}{l}\text { Under beater } \\
\text { or cylinder }\end{array}$ & $31-60$ & 0.38 & 0.46 \\
\hline
\end{tabular}

N.B. * Data on Shirley analyzer

* Cleaning efficiency Non-lint in waste to supplied raw stock Lint in waste to supplied raw stock
3-2-3. Power consumption by carding engine

The load for the wire of the carding engine is lessened by the better opening action and high efficiency cleaning by Model D Opener. Also damage to the wire is practically eliminated. The actual electric power consumption for carding is 300 watts for the conventional machine, 240 for Model D Opener.

\section{3-2-4. Blending uniformity}

Model D Opener gives better blending uniformity than the conventional machine does, as is proved by the following test: Raw stock of spun rayon $(70 \%)$ and black-dyed spun rayon $(30 \%)$ supplied to Hopper by the sandwich system and their DBO lap supplied to Model D Opener and the conventional opener showed, on examination, the blending uniformity rates indicated in Figure 7.

\section{3-2-5. Evenness of lap weight}

Table 4

\begin{tabular}{lccc} 
& $\begin{array}{c}\text { Cotton } 30^{\prime} \text { 's } \\
\text { Conventional } \\
\text { opener }\end{array}$ & $\begin{array}{c}\text { Model D } \\
\text { Opener }\end{array}$ \\
\hline Short-term variations of lap* & 4.62 & 3.30 \\
Yard-to-yard variation & 1.36 & 0.95 \\
\hline & $\begin{array}{c}\text { Spun rayon } \\
\text { Conventional } \\
\text { opener }\end{array}$ & $\begin{array}{c}30^{\prime} \text { s } \\
\text { Model D } \\
\text { Opener }\end{array}$ \\
\hline Short-term variations of lap* & 4.50 & 3.21 \\
Yard-to-yard variation & 1.50 & 1.05 \\
\hline
\end{tabular}

N.B. *The short-term variation of lap is evaluated by measuring the weight variations of the M.C.C. card sliver. Laps produced by Model $D$ opener and conventional opener are processed by M.C.C. card into sliver.' Sliver is cut every 6 yards-equal to about 2 -inch-long lap. cut pieces of sliver are weighted. Then the coefficient of weight variations is computed This coefficient of variations is approximately to the coefficient of weight variations of lap.

Examples of short-term variations of 30 's lap for cotton are shown in Figure 8.

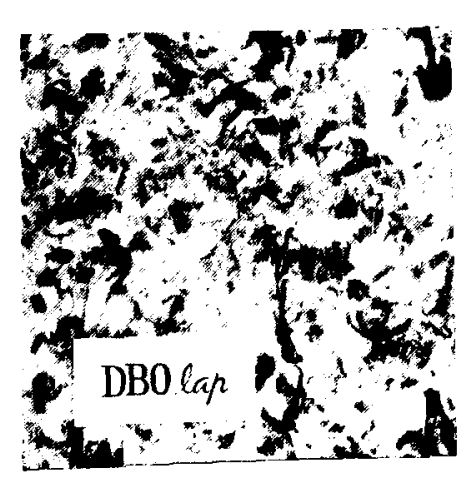

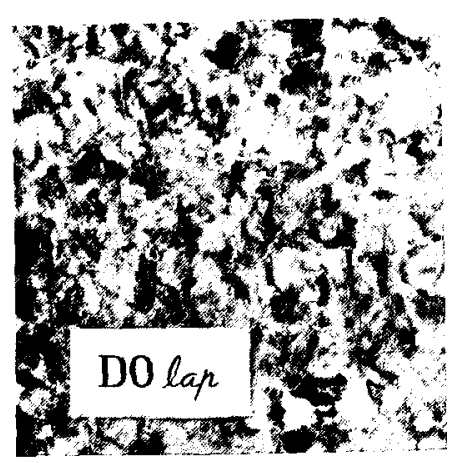

Fig. 7

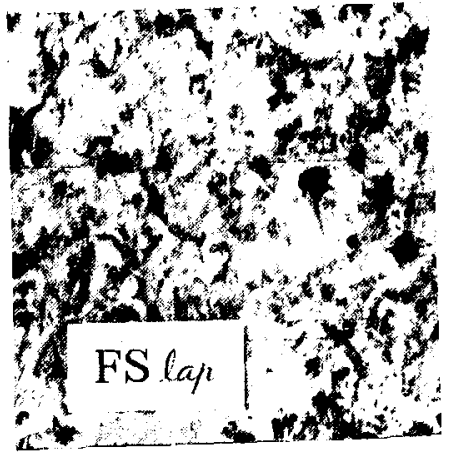


(A) Cotton $30^{\prime} \mathrm{s}$

Table 5

\begin{tabular}{|c|c|c|c|c|c|c|c|c|}
\hline & & \multirow{2}{*}{ Raw stock } & \multicolumn{3}{|c|}{ Products } & \multicolumn{3}{|c|}{ Waste } \\
\hline & & & DBO & FS & DÒ & DBO & FS & DO \\
\hline \multirow{3}{*}{$\begin{array}{l}\text { Upper half mean length } \\
\text { Uniformity of fiber length } \\
\text { Fiber strength by Pressley } \\
\text { tester }\end{array}$} & (inc) & 0.98 & 0.98 & 1.00 & 0.99 & 0.82 & 0.86 & 0.87 \\
\hline & (\%) & 77.9 & 77.6 & 76.2 & 78.6 & 75.6 & 74.4 & 74.9 \\
\hline & 83.1 & $\left(1,000 \mathrm{lb} / \mathrm{in}^{2}\right)$ & 86.4 & 78.8 & 84.2 & 78.8 & 78.8 & 78.9 \\
\hline
\end{tabular}

(B) Spun rayon $30^{\prime} \mathrm{s}$

\begin{tabular}{lccccl}
\hline & Raw stock & DBO & FS & DO & Note \\
\hline Max. length (mm,) & 52.75 & 52.00 & 52.25 & 52.00 & staple diagram \\
Effective length (mm,) & 50.00 & 49.00 & 49.00 & 49.00 & staple diagram \\
Mean length (mm,) & 47.46 & 46.52 & 46.76 & 46.62 & staple diagram \\
Short fiber $(\%)$, & 1.7 & 2.0 & 2.8 & 2.9 & staple diagram \\
Fiber strength (g/den,) & 5.63 & 5.40 & 5.50 & 5.48 & by Mackenzie fiber strength tester \\
Breaking elongation (\%) & 15.36 & 13.89 & 14.47 & 14.58 & by Mackenzie fiber strength tester
\end{tabular}

N.B. FS: Conventional Opener, DO Model D Opener

Upper half mean length and uniformity of fiber length are measured by Fibrograph.

Table 6

\begin{tabular}{|c|c|c|c|c|c|c|c|c|c|c|}
\hline & \multicolumn{8}{|c|}{ Cotton } & \multirow{2}{*}{\multicolumn{2}{|c|}{$\begin{array}{c}\text { Spun rayon } \\
30^{\prime} \mathrm{s}\end{array}$}} \\
\hline & \multicolumn{2}{|c|}{$10^{\prime} \mathrm{s}$} & \multicolumn{2}{|c|}{$20^{\prime} \mathrm{s}$} & \multicolumn{2}{|c|}{$30^{\prime} \mathrm{s}$} & \multicolumn{2}{|c|}{$40^{\prime} \mathrm{s}$} & & \\
\hline & FS & DO & FS & $\mathrm{DO}$ & FS & DO & FS & DO & FS & DO \\
\hline $\begin{array}{l}\text { Coefficient of variation } \\
\text { of yarn counts }\end{array}$ & 2.57 & 2.36 & 2.45 & 2.28 & 2.27 & 2.12 & 1.20 & 1.18 & 1.79 & 1.62 \\
\hline Lea strength $(\mathrm{lb})$ & 189.2 & 190.1 & 85.9 & 86.0 & 67.7 & 67.7 & 51.4 & 51.5 & 69.5 & 69.4 \\
\hline Uster evenness (\%) & 14.37 & 14.13 & 14.51 & 14.21 & 15.81 & 15.55 & 16.40 & 16.02 & 13.13 & 13.08 \\
\hline \multicolumn{11}{|l|}{ Yarn appearance } \\
\hline Evenness* & 140 & 140 & 140 & 143 & 140 & 141 & 145 & 145 & 159.2 & 163.5 \\
\hline Neppiness* & 150 & 150 & 144 & 147 & 140 & 143 & 140 & 144 & 200 & 200 \\
\hline
\end{tabular}

N.B. * This test and its evaluation are according to Japanese Industrial Standard L-1101 for cotton and L-1501 for spun rayon.

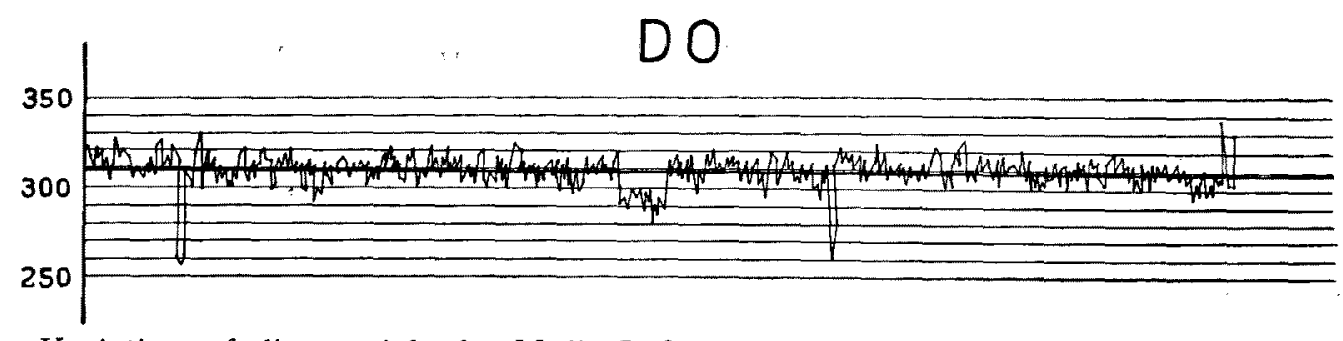

Variations of sliver weight for Modle D Opener's lap coefficient of variations-2.29\%

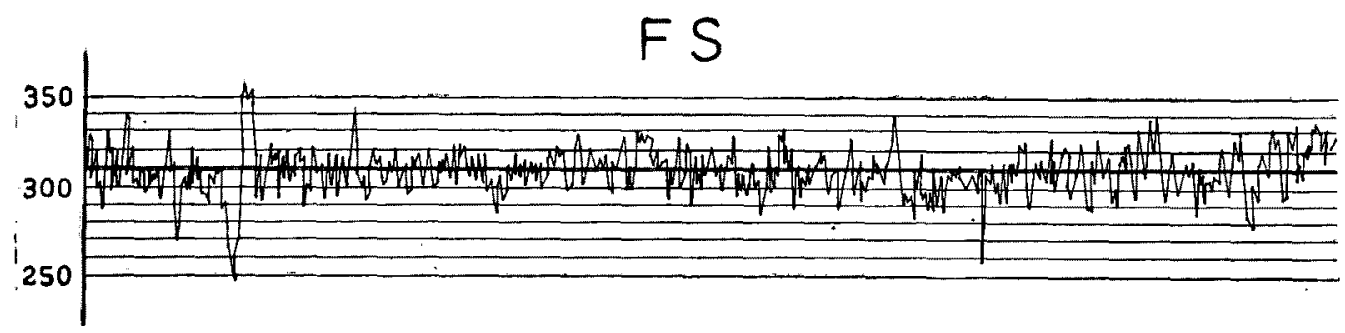

Variations of sliver weight for conventional Openes's lap coefficient of variations-4.60\% Fig. 8 
The licking of lap is prevented completely by the controlled stripping rail referred to to earlier.

\section{3-2-6. Damage to fiber}

The damage to fiber in operation by Model $D$ Opener is negligible. Table 5 shows the means of the upper half means, uniformity of fiber length and fiber strength by Pressley tester.

\section{3-2-7. Quality of yarn}

The respective qualities of yarns produced by the conventional opener and Model D Opener are shown in Table 6. Model D Opener shows less variation of counts and better lea strength, Uster evenness and rayon appearance.

\section{Conclusions}

The merits of Model D Opener may be summed up thus:

(1) Mod'el D Opener opens stock materials effectively without fiber damage.

(2) Cleaning efficiency of Model D Opener is excellent.

(3) Uniform weight of lap is obtainable by Model D Opener.

(4) The blending of lint by Model D Opener is excellent.

(5) The load of carding action of wire and damage to wire can be decreased by the lap of Model D Opener.

These advantages apply to the rayon as well as the cotton spinning system. The arrangement of blowing and picking room machines is as follows:

\section{(A) Cotton sinning}

Course counts:

Bale Opener - Hopper Mixed - SRRL Opener - Hopper Opener - Hopper Feeder - Double Cylinder Opener with Lap Machine.*

Medium counts :

Bale Opener-Hopper Mixer-SRRL Opener - Hopper Opener-Hopper FeaderSingle Cylinder Opener with Lap Machine.*

(B) Spun rayon

Opener-Hopper Opener-Hopper Feeder-Single Cylinder with Lap Machine.***

* 1st cylinder is Model D Opener with spiked cylin. der.

2nd cylinder is Model D Opener with saw-toothed cylinder.

** Single cylinder opener is Model D Opener with saw toothed cylinder.

*** Single cylinder opener is Mobel D Opener with spiked cylinder.

\section{Acknowledgement}

We acknowledge the cooperation of Ohtori Kiko Co., Ltd., Tomiyasu, Tottori City, Tottori Prefecture, Japan, who produced the model machine and service machines. 